\title{
Exposição da Audiência aos Meios: avanços da abordagem de Usos e Gratificações
}

\section{Social Media Audience: approach advances of Uses and Gratifications}

\author{
Raquel Marques Carriço Ferreira' \\ Professora Adjunta da Universidade Federal de Sergipe, com atuação no curso de Publicidade e Propaganda e no Programa de \\ Pós-graduação em Comunicação. Doutora pela Universidade Nova de Lisboa (2011) e Mestre pela Universidade Metodista de \\ São Paulo (2003). \\ $<$ raquelcarrico@gmail.com>
}

\section{RESUMO}

A abordagem de Usos e Gratificações possui uma tradição influente na pesquisa da audiência tratando dos aspectos que levam o receptor a selecionar e a se expor aos diferentes meios e conteúdos da comunicação. O pressuposto básico da sua proposição é que, através das experiências e reflexões da audiência sobre os conteúdos das mídias, ela relaciona quais materiais lhes são gratificantes ou úteis. Por certo, o modelo de U\&G se expandiu de tal forma que não mais falamos em uma teoria de U\&G, mas sim, em um esquema de multiteorias. O presente artigo demarca o "estado da arte" deste importante referencial, apontando suas formulações principais evidenciadas pelo uso do método da revisão de literatura bem como dos resultados de uma investigação bibliométrica.

Palavras-chave: Usos e Gratificações. Esquema de Multiteoria. Marcos Teóricos.

\begin{abstract}
The approach of Uses and Gratifications has an influential tradition at the audience research dealing with the factors that led the receiver to select and to expose to different media and communication content. The basic assumption of this proposition is that, through the experiences and reflections of the audience on the media contents, they relate which materials are rewarding or useful. Certainly, the model of U\&G expanded so much that we do not talk about a theory of U\&G anymore, but, in a multi theory scheme. This article aims to introduce the "state of art" of this important reference, pointing its main formulations evident by the use of literature review and the results of a bibliometric research.
\end{abstract}

Keywords: Uses and Gratification. Multi Theory Scheme. Theoretical landmarks.

\section{Introdução}

O longo percurso dos estudos sobre a audiência e a recepção dos meios da comunicação social nos mostra um acúmulo de conhecimento estruturado por eixos analíticos dos processos básicos do receptor. Tais processos se referem às respostas que os membros da audiência dão aos meios, como respostas de exposição, de recepção, respostas atitudinais e comportamentais. Segundo

1 Colaborou com o levantamento de dados Dhione Oliveira Santana (aluno especial do PPG de Comunicação e Sociedade da Universidade Federal de Sergipe. 
Ruótolo, o propositor do enfoque, as análises teóricas passam a eleger um grupo de respostas como sendo seu eixo analítico da audiência porque "não existe uma teoria geral que explique o receptor desde o momento que decide a expor-se a um conteúdo da comunicação até as suas últimas consequências comportamentais" (Ruótolo, 1998, p.160).

As análises teóricas produzidas pela abordagem de Usos e Gratificações se encontram sob as preocupações da exposição, e se desenvolveram sobre o interesse do ato de decisão e escolha do receptor em se expor aos meios e conteúdos da Comunicação Social. O campo de interesse desta abordagem, portanto, se encontra no processo de decisão de consumo.

Uma proposta audaciosa para o conhecimento científico da comunicação social da década de quarenta foi a transposição dos estudos dos efeitos dos meios para uma nova percepção, onde o processo da comunicação social se inicia com as intenções do receptor de exposição às mensagens dos meios. Tal propositura, entretanto, não foi a única a revolucionar as noções sobre o processo da comunicação advinda do modelo de U\&G. Muito embora desenvolvido de modo moroso, o referencial de U\&G se expandiu de tal forma que não falamos em uma teoria de Usos e Gratificações, e sim, em um esquema de multiteorias "que ilustram diversas estratégias de integração teórica" (Palmgreen, Wenner e Rosengren, 1985, p.15).

Assim como posto, o esquema de Usos e Gratificações demandou um desenvolvimento a que este texto busca sintetizar.

\section{O esquema multiteórico de U\&G}

Os estudos iniciais datados da década de quarenta foram levados a cabo segundo uma perspicaz descrição dos motivos pelo qual a audiência selecionava e consumia os diversos meios como rádio, jornal, cinema, revista, quadrinhos, etc. (Blumer e Katz, 1974, Rubin, 1998 e McQuail, 2003). As questões centrais que guiavam tais investigações eram, por que é que as pessoas usam os meios e para o que os usam?

Em uma etapa seguinte, dada nos anos entre as décadas de cinquenta e início dos anos setenta, tais pesquisas passam a dedicar-se à definição e operacionalização de múltiplas variáveis que resultaram como explicativas dos diferentes padrões de exposição aos meios.

Focadas nas tipologias do uso, foram encontradas "gratificações e necessidades" que relacionadas a papéis sociais e disposições psicológicas, reforçavam ou debilitavam uma conexão com um referente da comunicação (Rubin, 1998). Papéis sociais e disposições psicológicas conectados com materiais 
específicos da comunicação podem ser exemplificados simploriamente como nos casos de indivíduos entediados que possuem como padrão de consumo dos meios, conteúdos de diversão, indivíduos em contexto de vida de risco (instabilidade econômica/financeira, guerras, epidemias), que possuem o hábito o consumo de conteúdos jornalísticos, ou indivíduos que pais de crianças pequenas se expõem aos conteúdos infantis para entretê-las por algumas horas. Finn e Gorr (1988) encontraram associações positivas entre a timidez, solidão e uso da televisão por motivos de compensação social, por exemplo. Tais conexões demonstravam "tipologias da interação pessoas-meios".

Este foi o início de uma fase mais conceitual para a perspectiva, que cresceu em conjunto com o interesse pelo impacto televisivo. As relações entre os contextos da audiência, os motivos de audiência e as satisfações gratificadas pelos meios, aportaram uma estratégia de investigação mais explicativa e adequada para uma grande variedade de processos comunicativos mediados pelos diversos aparatos tecnológicos (Wimmer e Dominick 1996, p. 368-369).

Blumer e Katz (1974) apontam que foi com a revisão do conjunto de pesquisas desenvolvidas nos EUA, Grã-Bretanha, Suécia, Finlândia, Japão e Israel, que o interesse de estudo da tradição pôde ser sistematizado, sendo basicamente: (1) as origens sociais e psicológicas das (2) necessidades, que geram (3) expectativas de satisfação dos (4) meios ou outras fontes, que levam a (5) padrões diferentes de exposição resultando em (6) gratificações das necessidades e (7) outras consequências.

Em síntese, a concepção central formulada era a de que a estrutura e as circunstâncias do contexto social/pessoal em conjunto com a disponibilidade dos meios de comunicação promovem um ambiente que proporciona o estabelecimento dos hábitos gerais de uso dos meios e dos conteúdos. Padrões de exposição se estabelecem segundo a experiência de audiência dos meios e a comprovação de obtenção de gratificações buscadas, ou, caso os meios não demonstrem capacidade para esta operação (gratificação do seu usuário), a procura de outras fontes se estabelece.

Dada a esta cadeia de processos a exposição aos meios passa a ser considerada segundo forças complexas e interatuantes. Estas forças são genericamente sintetizadas em "necessidades", "anseios" ou "desejos" que se transformam em motivos para a procura dos meios/conteúdos e/ou outras fontes de satisfação:

As décadas seguintes também foram reveladoras para U\&G. Lin (1996) acusa, por exemplo, um desenvolvimento intenso voltado para questões mais amadurecidas relacionadas à metodologia e princípios teóricos. Blumer e Katz 
Figura 1 - Modelo básico da teoria de Usos e Gratificações

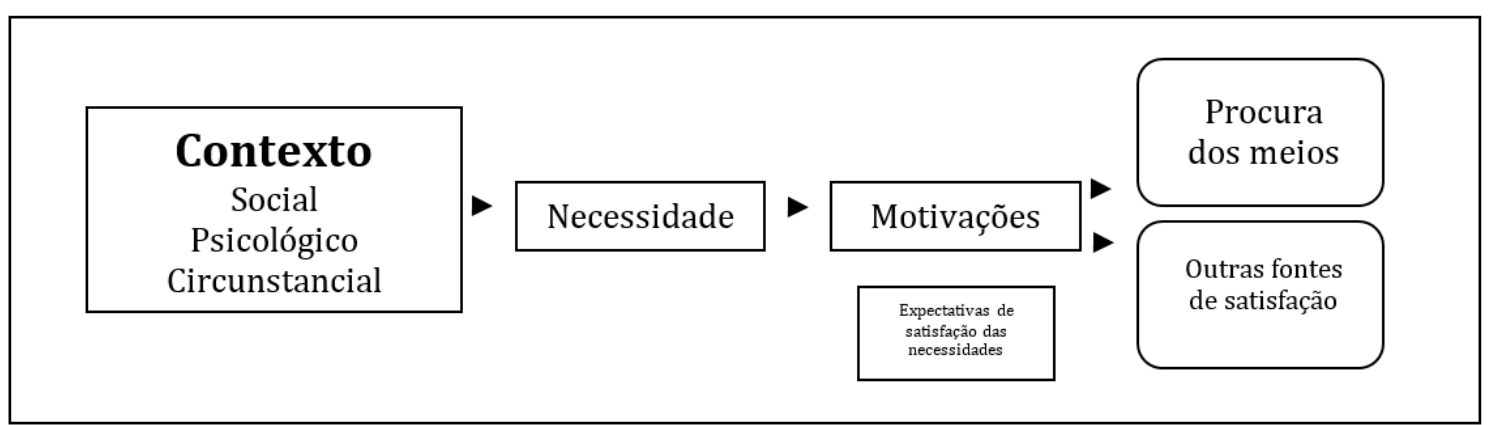

Fonte: a autora.

(1974, p.13) diziam ser esta fase caracterizada por prover explicações sobre outras facetas do processo da comunicação com a audiência, como por exemplo, vista em Perse 1986; Perse e Rubin 1988, 1987; Swanson, 1987; Wenner, 1986 (citado por Lin, 1996), que trabalham o relacionamento da busca de gratificações com os níveis de exposição aos meios; assim como a apresentação da distinção conceitual entre motivações instrumentais e ritualizadas².

Porque foi nessa terceira fase que muitas "suposições foram cristalizadas" que passos decisivos foram tomados em direção a uma integração teórica mais ampla. Algumas dessas suposições chaves tomaram proporções destacadas, como as de McQuail e outros (citado por Palmgreen, Wenner e Rosengren, 1985, p.13), em que considerava que a (1) audiência é ativa, assim (2) os usos dos meios podem ser objetivamente direcionados, mesmo que (3) competindo com outras fontes de satisfação de necessidades. A audiência preliminarmente considera (4) certas conexões entre necessidades e as escolhas dos meios, e assim, (5) o consumo dos meios acaba por preencher uma gama variada de gratificações, embora (6) o conteúdo dos meios isoladamente não pode ser usado para prever padrões de gratificações corretamente, isso porque (7) as características dos meios estruturam o grau em que as necessidades podem ser gratificadas em diferentes oportunidades, e além do mais, porque (8) as gratificações obtidas podem ter suas origens nos conteúdos dos meios, nas exposições sobre estes, e /ou na situação social ao qual a exposição acontece (como em uma situação de recepção em grupo, familiar ou entre amigos, cuja

2 Rubin (1984) e Rubin e Perse (1987) em seus respectivos estudos delinearam "motivações ritualizadas", baseadas em um relacionamento menos ativo da audiência em interação com a televisão, com um comportamento habitual, menos seletivo, e, portanto, com um consumo mais generalizado da programação. Motivações instrumentais se relacionam com uma tipologia da audiência televisiva mais "ativa", seletiva, envolvida e ou engajada no consumo televisivo, que no geral "usa" os conteúdos para resolução de problemas pessoais, tomada de decisões e ou reflexões das suas condições circunstanciais. 
gratificação não se encontra necessariamente com o conteúdo transmitido, mas na situação de sociabilização que o conteúdo proporciona).

É coma sedimentação da pesquisa que o esquema multiteórico de Usos e Gratificações foi principiado, impulsionado essencialmente, pela construção de seis categorias teóricas principais de estudo. Alinhadas ao paradigma de U\&G, estas categorias não só deram impulso ao desenvolvimento da quarta fase da pesquisa, mas também estabeleceram com maior precisão, o conhecimento sobre as condições pelo qual as pessoas selecionam e consomem as mensagens dos meios de comunicação. O resultado de tal esforço foi "a emergência de uma estrutura teórica complexa" (Palmgreen, Wenner e Rosengren, 1985, p.16), que localiza o processo de gratificação em uma perspectiva global:

A estrutura ou modelo geral apresentado por Palmgreen, Wenner e Rosengren (1985) tem em conta no processo da procura dos meios, a interação entre a estrutura social/cultural e as características pessoais, que originam as

Figura 2 - Modelo Geral de Usos e Gratificações - baseado em Palmgreen, Wenner e Rosengren, 1985

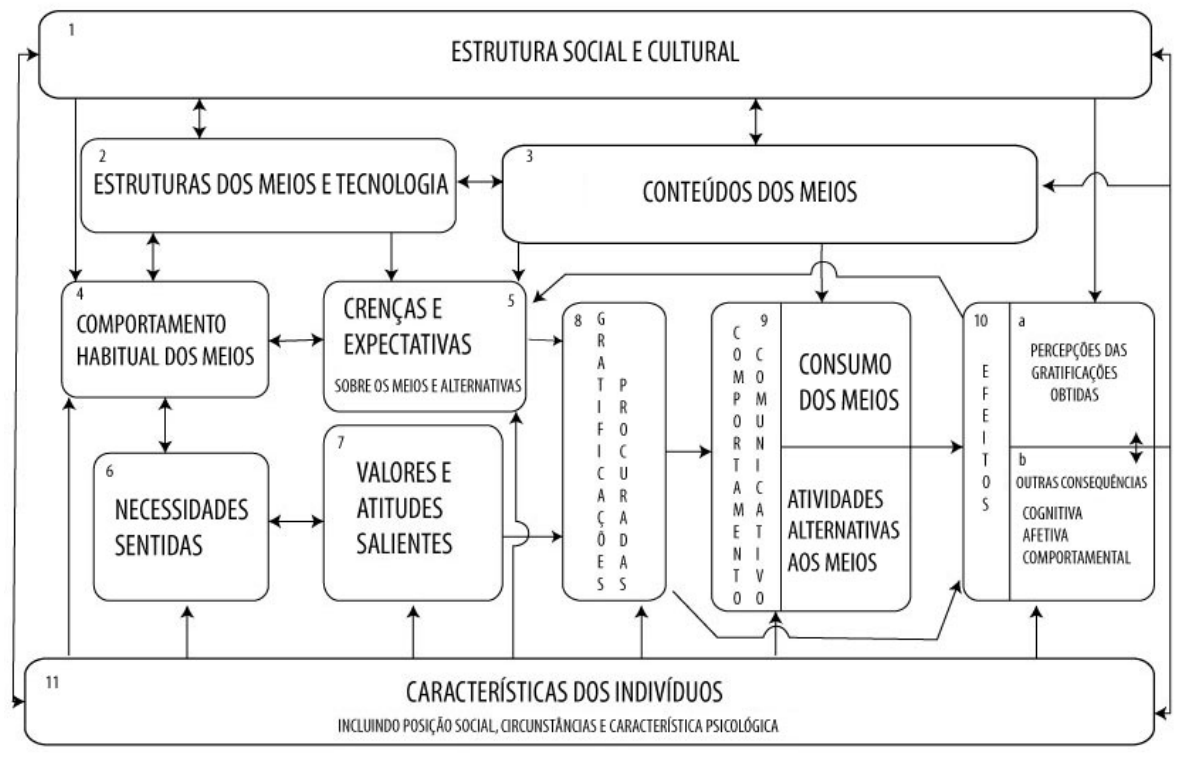

Fonte: Palmgreen, Wenner e Rosengren, 1985.

necessidades, valores, disposições, e que por consequência, impulsionam motivos para o comportamento que eventualmente é direcionado aos meios. Também a estrutura tem em conta, elementos fundamentais para os usos dos meios e seus conteúdos, como as avaliações perceptivas das gratificações obtidas, 
e a estrutura de oferta dos meios entre outros, como fatores intervenientes no processo de exposição do receptor.

Neste esquema"multivariado" apresentado por U\&G, não há elementos de desempenho central. Os mais próximos de um papel destacado à exposição aos meios são as gratificações procuradas ou motivos, o que evidencia desse modo, "a natureza motivacional da teoria de Usos e Gratificações". Este posicionamento indica também que as variáveis não fornecem explicações satisfatórias sobre o comportamento seletivo dos receptores dos meios, quando tomadas de forma isoladas.

Dado ao fundamento da estrutura teórica das gratificações apresentado, o texto passa a explorar as seis categorias mais destacadas alinhadas ao modelo de U\&G, apresentadas em cinco diferentes tópicos, respectivamente, (1) as origens sociais e psicológicas das gratificações dos meios; (2) a abordagem do valor da expectativa; (3) a atividade da audiência; (4) gratificações e o consumo dos meios e (5 e 6) gratificações procuradas e obtidas, e gratificações e os efeitos dos meios.

\section{Origens sociais e psicológicas das gratificações dos meios}

Um ponto de vista difundido entre grande parte dos pesquisadores de usos e gratificações é que os membros da audiência não experimentam os meios de comunicação social como indivíduos isolados, "mas membros de grupos sociais organizados participantes de um meio cultural" (Palmgreen, Wenner e Rosengren, 1985, p.19). Desse modo, muitos dos motivos que guiam os receptores à exposição dos meios, têm suas origens no meio social.

Tais estudos em síntese estabelecem laços empíricos entre as gratificações e variáveis como idade, grau de educação, integração aos grupos sociais, ou condições de mobilidade ou renda. Mais recentemente, estudos "tipológicos" têm avançado com a descrição e operacionalização mais complexa dos elementos antecedentes do receptor, (escolaridade, classe social, perspectiva de vida etc.) na associação do comportamento motivado dirigido aos meios. Tais variáveis observadas de forma integrada acabam por estabelecer uma "construção tipológica do consumo dos meios" a partir da evidência de diversas variáveis/condições da exposição (antecedentes $X$ intensidade de exposição, antecedentes $X$ o consumo dos gêneros de conteúdos, etc.).

Passos como estes partiram inicialmente de tentativas de fornecer uma estrutura teórica genérica dos antecedentes que modelavam os padrões de audiência, apoiados no exame isolado das condições como gênero, idade, classe social etc. Com resultados frustrados da conexão entre tais variáveis 
e a exposição aos meios, estudiosos da área vislumbraram a necessidade da combinação das diversas circunstâncias sociais/ psicológicas para se superar a falta de uma estrutura que associasse sistematicamente as gratificações às suas origens.

Um trabalho pioneiro nesse sentido foi conduzido por Blumer (1979). Desenvolvido no centro para pesquisa em televisão da universidade de Leeds, o trabalho foi projetado para investigar as fontes sociais/ pessoais das satisfações nos meios, baseado em um exame de aproximadamente mil adultos britânicos. Blumer realizou o exame das associações dos aspectos das experiências pessoais dos receptores de acordo com os procedimentos do AID (detector automático de interação) em que pôde determinar quais experiências em conjunto seriam mais destacadamente operativas para a origem da motivação e subsequente consumo dos meios.

Estudos como este são conduzidos com a tomada das experiências particulares da audiência que demonstram explicar a variação da satisfação com os meios, muito embora ainda estejam em desenvolvimento, as tentativas de estabelecimento das prescrições teóricas que envolvem os elementos sociais e psicológicos na origem das motivações dirigidas aos meios.

\section{Abordagem do valor da expectativa}

Sob a perspectiva do microprocessamento das mensagens dos meios da comunicação social ${ }^{3}$, as exposições foram entendidas como reguladas pelas gratificações percebidas nos conteúdos. Quando identificada uma experiência significativa ou valiosa pelo receptor, algum esforço para a repetição do consumo da mensagem ocorria, desse modo, a audiência dos conteúdos dos meios se mostrou motivada.

Os motivos em síntese revelaram o sentido que guia o receptor ao consumo das mensagens, resultado do reconhecimento das satisfações obtidas. No trabalho de Palmgreen e Rayburn (1985) sobre "a abordagem do valor da expectativa para as gratificações dos meios" é posto que os elementos essenciais do processo seletivo são as (1) expectativas ou motivações, ou seja, a probabilidade percebida de que o consumo de um conteúdo terá uma consequência particular (obtenção de uma gratificação), e a (2) avaliação desse resultado pelo membro da audiência, que é o grau de afeição, prazer relativo à consequência particular esperada. De fato, a exposição aos meios envolve

3 O que dá destaque aos estudos conduzidos pela abordagem dos processos psicológicos da audiência. 
não somente as gratificações para o seu empreendimento, mas também, um índice subjetivo de prazer avaliado pelo receptor sobre sua experiência com os meios, que acaba por determinar com que força o receptor se dirige às novas exposições, com que forma lida com os conteúdos, com que intensidade se expõe a eles etc. Em conjunto, são esses dois fatores "chaves" que influenciam os padrões de exposição à comunicação social.

Segundo tal proposição, receptores selecionam os conteúdos dos meios da comunicação social na base da probabilidade percebida de que os seus conteúdos Ihes proporcionarão uma experiência de "gratificação ou uso", e esta experiência é avaliada hedonicamente ${ }^{4}$ . Esta posição é consolidada pela fusão explícita de Usos e Gratificações com os conceitos do Valor da Expectativa, fundamentada no trabalho de Fishbein (1963) e Fishbein e Ajsen (1975, citado por Palmgreen e Rayburn, 1985), expressos formalmente sob a fórmula:

A par desse princípio, um indivíduo se expõe a um determinado conteúdo/ meio porque este possui, ainda que subjetivamente, certa probabilidade de satisfação e uso. Entram em jogo nesse momento, as percepções do receptor que avalia o "grau de satisfação obtido com a experiência de exposição". Neste contexto, uma nova geração de estudos tem contribuído significativamente para

- Figura 3 Valor da expectativa das gratificações dos meios, Palmgreen e Rayburn (1985)

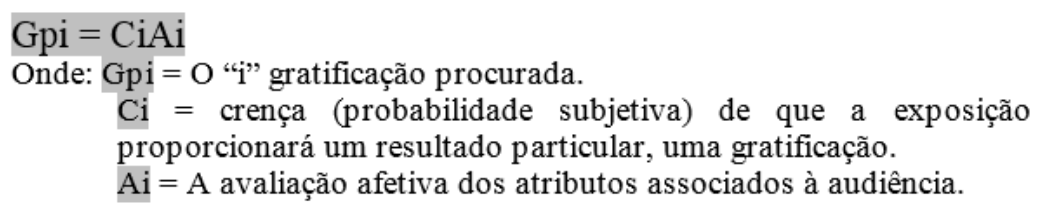

Fonte: Palmgreen e Rayburn (1985).

a consolidação das proposições que avançam com as questões do entendimento das forças que governam os usos dos meios da comunicação social. Observemos um trabalho investigativo que retoma a estrutura da "abordagem do valor da expectativa para as gratificações dos meios" ao destacar um processo em que as 1.expectativas e as 2.avaliações influenciam a seleção e audiência dos conteúdos da comunicação social.

4 Portanto, estes dois elementos são conceitualmente e analiticamente distintos (McQuail e Windal, 1993, p. 136). 
Assistir às telenovelas em Portugal foi o tema investigado na Universidade Nova de Lisboa (Ferreira, 2011). Em síntese, o trabalho reforça os achados do princípio de que a experiência gratificante avaliada afetivamente se transforma em um energizador para exposições agora padronizadas. A exposição padrão dos membros da audiência aos conteúdos das telenovelas se inicia então com uma experiência casual, em que o receptor identifica uma gratificação e avalia o seu devido "valor", passando assim a desenvolver (a partir do resultado da avaliação) "certo" relacionamento com o material em questão. Dependendo do valor afetivo e do grau de correspondência entre as expectativas e a oferta das gratificações nas telenovelas, os receptores entrevistados estabeleceram desde uma relação comprometida com seus conteúdos, com uma audiência empenhada, determinada e dedicada, como também demonstraram padrões de consumo em posição oposta a estes padrões, com um consumo fortuito, não envolvido e eventual.

A articulação dos resultados encontrados se alinhou à abordagem do valor da expectativa das gratificações que destaca as avaliações de valor das gratificações pelos membros da audiência. Embora o reconhecimento das reações afetivas seja uma condição relevante para a determinação dos processos de seleção e audiência dos conteúdos, tal aspecto foi negligenciado por diversas tradições, mesmo U\&G, até meados da década de 1980, quando é incorporado nas concepções teóricas dessa tradição de estudos (Blumer, 1985 e Palmgreen e Rayburn, 1985, p.63).

De acordo com Cohen, Fishbein e Ahtola (1972), as reações afetivas são os sentimentos positivos e negativos (portanto afetivos) construídos sobre uma formulação cognitiva, elaboradas sobre os atributos reconhecidos nos meios de comunicação. Desse modo, o modelo estabelecido pelo estudo em destaque precisou o dimensionamento da intervenção das reações afetivas do receptor (sentimentos de prazer) sobre os atributos percebidos nas telenovelas, cognitivamente formulado pelo receptor.

\section{A Atividade da Audiência}

A ideia de um receptor passivo, apático, inerte, foi confrontada com os estudos empíricos de U\&G. Desde o princípio do seu desenvolvimento, a abordagem de U\&G apontou para um posicionamento oposto a este, demonstrando em seus resultados um indivíduo variavelmente ativo, voluntário e diversificadamente motivado diante dos meios. Para além das 
muitas evidências empíricas, Levy e Windahl (1985) se dedicaram a especificar a "tipologia da atividade da audiência", construindo suas observações sobre duas dimensões orientadoras, a primeira nos termos de seletividade, envolvimento e utilidade, alinhavada com uma segunda dimensão que é temporal, antes durante e depois da exposição aos meios.

Tais tipologias da atividade da audiência resultariam, em suma, nos seguintes princípios:

1. A seletividade é um processo de escolha não fortuita de uma ou mais alternativas de comportamentos, percepções ou conhecimentos relacionados aos meios. A seleção antes da exposição propriamente dita reflete a decisão individual de consumo dos meios fundamentada nas percepções aprendidas e experiências anteriores dos meios. Também a seleção durante a exposição é compatível com o modelo. $O$ princípio da percepção seletiva sugere que os membros da audiência deem mais atenção a algumas partes da totalidade da mensagem do que outras. Estudos sobre leitores de jornais têm demonstrado, por exemplo, que diferentes indivíduos que leem o mesmo jornal focam sua atenção em seções diferenciadas. A seletividade posterior à exposição efetiva dos meios por sua vez é verificada com o processo de recordação seletiva.

2. O envolvimento da audiência com os meios está relacionado ao grau em que o receptor percebe uma conexão entre ele e os conteúdos dos meios, segundo a interação que este mantém com as mensagens. $\mathrm{O}$ envolvimento anterior à exposição sugere, por exemplo, que algum nível de antecipação pode associar-se com o uso projetado dos meios, o que poderia demandar do receptor, certo nível de apreensão para a exposição (jantar mais cedo para se dedicar às telenovelas é um exemplo). Durante a exposição, o envolvimento se relaciona aos níveis de consciência sobre as mensagens consumidas, reveladas, pelos níveis de atenção dedicados aos conteúdos (não permitir crianças no local de exposição aos conteúdos prediletos ou costurar enquanto se assiste à televisão, determinaria o grau de envolvimento do receptor com o programa assistido). O envolvimento posterior à exposição sugere que o indivíduo pode vir a participar de atividades relacionadas ao material objeto de seu envolvimento, como colecionar 
revistas, figurinhas, ou o que quer que esteja conectado ao produto mediático ao qual o receptor se expõe.

3. A noção de utilidade condensa o processo da audiência em antecipar os usos dos meios de comunicação para os seus propósitos pessoais. A utilidade anterior à exposição é exatamente o grau de consciência da expectativa que o receptor deseja gratificar e a noção de onde a expectativa pode ser gratificada (- "agora vou relaxar com minhas telenovelas", ou, - "preciso ver o capítulo do casamento da novela para me informar sobre como me vestir no casamento da vizinha"). Durante a exposição tal utilidade se refere ao próprio processo motivado, pois nem sempre a exposição se relaciona a uma busca específica ou a uma expectativa a ser satisfeita; "muitas das gratificações cognitivas e afetivas obtidas com os meios se experimentam na situação de exposição". A utilidade depois da exposição se relaciona aos diversos usos dos materiais dos meios em seu contexto imediato; conversas a respeito dos conteúdos ou a ação de compra baseado em tais materiais são exemplos ilustrativos do seu conceito.

Em concordância com a ideia inicial posta pelos autores Levy e Windahl (1985) de que o receptor é "ativo", os conceitos da "atividade da audiência" em avaliação por estudos subsequentes comprovaram que quanto mais motivada demonstrava ser a audiência, mais empenhados os receptores se mostravam nas suas atividades com os meios.

Também não foram poucos os estudos que ratificaram empiricamente os aspectos da atividade da audiência, como seletividade e utilidade. Rubin e R. Rubin (1982, citados por Palmgreen, Wenner e Rosengren, 1985).

\section{Gratificações e o consumo dos meios}

Os estudos dedicados ao comportamento motivado da exposição aos meios se desenvolveram de forma difusa, particularmente nas duas primeiras fases do desenvolvimento do paradigma U\&G. Duas são as categorias de estudos pertencentes a essas investigações, os estudos da tipologia dos motivos dos meios, e os estudos das conexões entre gratificações e os conteúdos dos meios.

De forma geral, os estudos da primeira categoria investigativa permitiram apenas a identificação dos motivos direcionados aos meios. O estudo de Ferguson e Perse (2000) pode ilustrar tal perspectiva. Com o objetivo de explorar as similaridades entre televisão e a Internet, eles inquiriram usuários de ambos 
os meios e encontraram três motivos similares para o uso da televisão e Web: entretenimento, passatempo, e relaxamento. Também mais recentemente, Book e Grady (2005) examinaram os entusiastas do rádio satélite e encontraram que seus receptores consumiam ainda as rádios tradicionais por motivos de vigilância e integração social.

Papacharissi e Mendelson (2007) revelaram que os motivos mais salientes para o consumo dos "reality shows" é passatempo e entretenimento. Muito embora o consumo dos meios seja certamente constrangido por fatores estruturais como a oferta dos conteúdos ou disponibilidade do receptor para o consumo, o que tais estudos têm evidenciado é que as motivações desempenham papel fundamental na mediação do comportamento dos meios.

A segunda categoria de estudos em questão por sua vez fixa-se na demonstração das associações empíricas entre as gratificações e a exposição seletiva, ou mais especificamente, das gratificações aos tipos ou gêneros de conteúdos transmitidos, por exemplo, na televisão. Tais investigações destacariam quais tipos de gratificações estariam associadas a que tipos de conteúdos dos meios; entretanto no geral, o consumo da comunicação social demonstra baixa ou moderada correlação entre as gratificações e as espécies de conteúdos da comunicação social.

O que as investigações têm evidenciado são "esquemas motivacionais multivariados" que conduzem o consumo dos meios e/ou conteúdos, de modo que "múltiplas motivações" passam a guiar a exposição a um ou mais conteúdo/ meio. Nessa perspectiva, a audiência acabaria por procurar meios ou conteúdos diversos baseada na satisfação de uma gratificação em específico, como também demonstraria consumir uma única oferta comunicativa para satisfazer diversas gratificações.

\section{"Gratificações buscadas e obtidas" e "Gratificações e efeitos"}

Foi nos primeiros anos da década de 1970 que os estudiosos da abordagem de U\&G destacaram a necessidade de distinguir conceitualmente gratificações buscadas e obtidas. Levy e Windahl, 1984; McLeod e Becker, 1981; McLeod e outros, 1982; Palmgreen e Rayburn, 1979; 1984; Palmgreen e outros, 1980; 1981; Rayburn e Palmgreen, 1983; 1984; Rayburn e outros, 1984; Wenner 1982; 1983; entre outros, (citado por Palmgreen, Wenner e Rosengren, 1985, p.27), em pesquisa apontam que "as gratificações buscadas demonstram moderada correlação com a correspondência das gratificações obtidas".

Tal declaração significa de fato a constatação de certa incidência ou baixa correlação entre estas duas variáveis, as gratificações buscadas e obtidas; 
uma percepção então significativa para o entendimento das expectativas que energizam o comportamento de exposição aos meios. A natureza do que a audiência procura e obtém é uma importante contribuição para a formação das percepções, crenças e avaliações dos atributos dos meios experimentados.

De forma sintética, o que é apontado pelas pesquisas desenvolvidas sob o interesse em destaque é que ambas as variáveis (gratificações procuradas e obtidas) se relacionam de forma distinta com a escolha dos conteúdos. Como examinado por Palmgreen, Wenner e Rosengren (1985), gratificações procuradas e obtidas em conexão com o valor da expectativa, fazem do comportamento de exposição ser modelado pelas gratificações correspondidas ou não correspondidas. Uma vez não havendo gratificações ou usos na exposição de um conteúdo, a audiência concebe uma percepção avaliativa negativa sobre o conteúdo, o que energiza um comportamento de procura de outros conteúdos/ eventos que a satisfaça. Uma vez consolidado a percepção de obtenção de gratificações em uma mensagem, é muito provável que se estabeleça uma exposição padrão ao conteúdo experimentado.

Também com destaque, é necessário expor o exame dos motivos da procura dos meios e os subsequentes "efeitos" da comunicação, que acabou por emergir das sugestões qualificadas do seu entrelaçamento. A fusão entre gratificações e efeitos dos meios tem estabelecido sérios pontos de negociação entre a exposição motivada aos meios e a capacidade de influência destes sobre seus receptores (Palmgreen, Wenner e Rosengren, 1985, p. 30).

Estudos produzidos por Becker, 1976; Blumer e McQuail, 1969; Bock, 1980; Nordlund, 1978; Roe, 1983; Rosengren e Windahl, 1977; Rubin, 1981; 1983; Rubin e R Rubin, 1982; Weaver, 1980; Wenner, 1982; 1983; Windahl et al., 1983; (citado por Palmgreen, Wenner e Rosengren, 1985), demonstraram como as gratificações são importantes variáveis para o largo espectro de efeitos dos meios, incluindo a aquisição de conhecimento; dependência dos meios; influência sobre atitudes e opiniões; percepções da realidade social; agendas estabelecidas; bem como outras relações importantes.

Esta abordagem teórica procura explicar os efeitos dos meios ligando os motivos para a audiência, comportamentos e conteúdos com outras características do processo da comunicação social. Mcleod e Becker (1974 citado por Rubin, 1998) notaram efeitos recíprocos entre exposição e gratificações nos meios porque as gratificações agiriam como determinantes de agendas estabelecidas. Também Blumer (1979) sintetizou três usos primários dos meios e propôs três hipóteses sobre os efeitos baseados nas gratificações: 1. Motivações cognitivas (busca de conhecimento, aconselhamento) irão facilitar obtenção 
de informação. 2. Diversão ou escapismo irão facilitar uma percepção mais fidedigna da audiência sobre os retratos sociais expostos no entretenimento. 3 . Motivação de identidade pessoal (receptores que buscam emular-se) promoverá a facilitação de efeitos de reforço.

Segundo Rubin (1998, p. 431), hipóteses como as expostas por Blumer têm tido repercussão, como nos estudos de Perse, 1990, Rubin, 1983, 1984, Rubin e Perse, 1987, Rubin e Rubin 1982, que observam ligações entre a procura de informações instrumentais e o ganho de informação durante campanhas políticas. Tais pesquisadores concluíram que os usos dos assuntos públicos transmitidos pelos meios de comunicação motivaram o crescimento do conhecimento político.

\section{Considerações finais}

As evidências empíricas oriundas dos inúmeros trabalhos investigativos conduzidos sob a abordagem de Usos e Gratificações suportam uma estrutura complexa de um modelo que suplanta os conceitos iniciais propostos na década de quarenta e cinquenta, como pode ser observado na Figura 2 deste texto. Desde a publicação da sua formulação inicial, gerações de estudos têm contribuído para a consolidação das proposições envolvidas no modelo geral de U\&G, que avançam com as questões do entendimento das forças que governam os usos pessoais dos meios.

De modo geral, a tradição de U\&G já organizou muito trabalho e continua a emprestar adicional elaboração e aplicação às pesquisas. Sob este aspecto, ela "é de fato mais flexível do que pode parecer e pode prover uma poderosa estrutura para observar os meios em um amplo contexto cultural e social" (McQuail, 1998, p.157).

Não é à toa que Swanson (1992) e Ruggiero (2000) afirmam que a emergência da comunicação mediada por computadores e plataformas móveis, reavivou incontestavelmente, um número sem precedentes de investigações norteadas pela perspectiva de U\&G. Internet, tecnologias digitais, convergência dos meios de comunicação que permitem interatividade, desmassificação e assincronia dos fluxos de comunicação alteraram de modo significativo os padrões de exposição e o consumo dos conteúdos da comunicação. U\&G pareceu um recurso adequado para retratar estes novos padrões.

Ruggiero (2000), por exemplo, menciona Ha e James (1998), que reavivam a procura de "padrões de consumo destas novas tecnologias convergentes" e Newhagen e Rafaeli (1996), que sugerem que em conjunto com teorias da comunicação interpessoal, a internet pode ter sua taxinomia revelada. De 
qualquer modo, este novo ambiente tecnológico prescindiria do entendimento das necessidades, motivações das pessoas que tomam parte de uma nova conjuntura de exposição e de trocas de mensagens.

Numa tentativa de especular o cenário presente das investigações abordadas por U\&G, exponho parte dos resultados de uma pesquisa bibliométrica ainda em fase de publicação, elaborada por mim em conjunto com Dhione Oliveira (Universidade Federal de Sergipe), em que estudamos 259 artigos encontrados em 12 bases repositórias de artigos científicos ${ }^{5}$ acessados pelo portal periódicos Capes, bem como em pesquisa das bases universitárias brasileiras que possuíam pós-graduação na área da Comunicação Social (o resultado da consulta destas últimas foi de 3 trabalhos encontrados).

As bases nos trouxeram 108 periódicos internacionais e nos proporcionaram a consulta de 499 artigos selecionados através das palavras chaves "Usos e Gratificações" postas em quatro línguas distintas, português, inglês, alemão e espanhol. A redução de 499 para 259 artigos ocorreu devido a repetição de títulos que estavam indexados em mais de um periódico. O período delimitado de estudo foi de 1979 ao início de 2014.

De fato, algumas observações se mostram úteis para determinar o estágio da aplicação de U\&G na atualidade ${ }^{6}$. Do universo investigado, encontramos até o ano de 1991, 02 artigos publicados, 0,77\% do total, de 1991 a 2000, 30 artigos, $11,58 \%$ do total, de 2001 a 2010, 130 artigos, o que representa 50,19\% do total dos artigos publicados, e de 2011 a 2014, 97 artigos, 37,45\% do total. As médias anuais de publicações de artigos dos anos 1991-2000 foi de 3 artigos/ano, de 2001 a 2010 foi de 13 artigos/ano, quadriplicando o nível produtivo, e de 20112014 , a média passou a ser de 24,25 artigos/ano, o que significou o aumento de 8 vezes a média da primeira década contabilizada (1991-2000). Este crescente número acompanhou a insurgência das novas tecnologias.

A investigação do comportamento da audiência junto às plataformas digitais e redes sociais figuram como sendo o objeto de pesquisa de 137 artigos, algo em torno de $52,89 \%$ do total dos artigos analisados, seguido pelas Mídias Audiovisuais, 61 artigos (23,55\%), Telefones e Dispositivos Móveis, 20 artigos

5 Scopus (Elsevier), Social Sciences Citation Index (Web of Science), OneFile (GALE), SciVerse ScienceDirect (Elsevier) Wiley Online Library, Science Citation Index Expanded (Web of Science), Sage Publications (CrossRef), SAGE Journals, Directory of Open Access Journals (DOAJ), Emerald Journals (Emerald Group Publishing), SpringerLink, PsycARTICLES (American Psychological Association).

6 O primeiro é considerar que não tomamos o universo de produção de estudos devido a limitações logísticas orçamentárias, o que reduz o alcance de nossas indicações. O Portal Capes dá acesso gratuito as bases de dados a ela vinculadas, através das universidades públicas federais, contamos assim, apenas com as bases cuja disponibilidade nos foi dada através do portal. 
(7,72\%), Jogos (nos mais variados dispositivos), 17 artigos (6,56\%), Revisões, Estudos Multiteóricos 16 artigos (6,17\%), e Mídias Impressas e consumo de Notícias com 8 artigos (3,08\%). Dentro dessa lógica de investigação de um novo ambiente tecnológico, vimos renascer o caráter da identificação dos padrões de consumo, usos e recompensas buscados com as comunicações em 128 artigos (49,42\%), bem como da consolidação dos comportamentos midiáticos correlacionados aos fatores endógenos e exógenos (antecedentes) que ligam os motivos para a exposição aos meios às suas origens psicológicas e/ou sociais (U\&G e fatores sociais 15,05\%, U\&G e fatores sociais/ psicológicos 13,89\%, U\&G e fatores psicológicos, 13,12\%). Revisões bibliográficas e de caráter reflexivo teórico representaram $8,49 \%$ dos 259 artigos analisados.

Tais dados indicam que, embora seja clara a evidência de um crescente uso da abordagem de U\&G em um contexto tecnologicamente inovador para a recepção, esta perspectiva foi tomada sob as estruturas mais básicas e elementares para revelar as forças que governam os usos de novos e tradicionais aparatos de comunicação.

Por fim, destacamos os métodos de estudo mais utilizados nos artigos observados. Sob os auspícios das análises estatísticas, $89,63 \%$ do material foi desenvolvido. Múltiplas estratégias de análise foram utilizadas, inclusive em conjunto, em que destacamos modelagem de equações estruturais; análises de correlação, análises de regressão e fatorial; estatística descritiva e métodos menos conhecidos como a Metodologia Q. Grande parte dos estudos que não se originou de uma abordagem qualitativa das variáveis investigadas partia declaradamente de estudos de terceiros que apontavam "pistas" de resultados a serem replicados em conjunto a questionamentos transversais aos primeiros.

Os 10,32\% das investigações qualitativas analisadas partiram de reflexões teóricas e revisões bibliográficas, de abordagens como a da Teoria Fundamentada em Dados, Estudos Experimentais, Etnográficos e de métodos bem mais difundidos em outras áreas do conhecimento como o Delphi.

Assim, se consolida segundo nossa análise, a aplicação dos métodos quantitativos e análises estatísticas, na abordagem de U\&G, porque tais métodos têm-nos dito muito sobre padrões gerais, tendências e relacionamentos, permitindo a sua generalização, com um grau de precisão aos quais os métodos qualitativos não nos permite obter. Nossa colocação não relega os métodos qualitativos ou interpretativos a um papel subordinado da sua utilização, muito pelo contrário, reconhecemos sua importância na obtenção de uma visão mais ampla e profunda dos fenômenos sociais ao qual podemos aplicar com êxito nos estudos da exposição aos meios. 
Referências

BLUMER, Jay e ELIHU, Katz. The uses of mass communications: Current perspectives on gratifications research. Beverly Hills: Sage Publications, p. 19-32 e 167-196, 1974.

BLUMER Jay G.. The Role of Theory in Uses and Gratifications Studies. Communication Research. London: Sage Publications, 1979. Disponível em: <http://crx. sagepub.com/cgi/content/abstract/6/1/9>. Acesso em: 8 jan. 2014.

BLUMER, Jay. The Social Character of Media Gratifications. In: ROSEGREN, Erik, WENNER, Lawrence e PALMGREEN, Philip. (Eds). Media Gratifications Research. Beverly Hills: Sage publications, p. 41-59, 1985.

BOOK, C. L. e GRADY, D. A. Consumer Adoption of New Radio Distribution Systems. NAB GRANT REPORT. 2005. Disponível em: <http://www.elon.edu/academics/ communications/connections/2005/aug 05/satelliteradio.pdf>. Acesso em: 10 abr. 2014.

COHEN, J. B., FISHBEIN, M. e AHTOLA, O. T. The Nature and Uses of Expectancy-Value Models in Consumer Attitude Research. Journal of Marketing Research, v. 9, p. 456-460, 1972.

FERGUSON Douglas A., PERSE Elizabeth M. The World Wide Web as a Functional Alternative to Television. Journal of Broadcasting \& Electronic Media, V. 44 n.2, spring. p.155- 174, 2000. Broadcast Education Association: Gale Group Broadcast Databases. Disponível em: <http://www.infotrac.galegroup.com>. Acesso em: 14 ago. 2014.

FERREIRA, Raquel Marques Carriço. A Experiência da Audiência das Telenovelas em Portugal. Tese de doutorado defendida na Universidade Nova de Lisboa, Lisboa, Portugal, 31 jan. 2011.

FINN, S. and M.B. GORR. Social isolation and social support as correlates of television viewing motivations. Communication Research 1.5, 135 - 158, 1988.

LEVY, Mark e WINDAHL Sven. The Concept of Audience Activity. In: ROSEGREN, Erik, WENNER, Lawrence e PALMGREEN, Philip. (Eds.). Media Gratifications Research. Beverly Hills: Sage publications, p. 11-37, 1985.

LIN, C. A. Looking back: The contribution of Blumer and Katz's Uses of Mass Communication to communication research. In: Journal of Broadcasting \& Electronic Media. Beverly Hills: Sage Publications, p. 574-581, 1996.

MCQUAIL, Denis e WINDAL, Sven. Communication Models for the study of Mass Communication. 2 e. New York: Longman, 1993.

MCQUAIL, Denis. With the Benefit of Hindsight: reflections on Uses and Gratifications research. In: DINCKINSON, Roger; HARINDRANATH, Ramaswami e LINNÉ, Olga. 
Approches to Audiences: a Reader. London: Arnold publishers, p. 151-165, 1998.

MCQUAIL, Denis. Teoria da Comunicação de Massas. Tradução de Carlos de Jesus. Lisboa: Fundação Calouste Gulbenkian, 2003.

PALMGREEN, Philip e RAYBURN, J.D. An Expectancy-Value Approach to Media Gratifications. In: ROSEGREN, Erik; WENNER, Lawrence e PALMGREEN, Philip. (Eds.). Media Gratifications Research. Beverly Hills: Sage publications, p. 6172, 1985.

PALMGREEN, Philip, WENNER, Lawrence, ROSENGREN, E. Uses Gratifications Research: The Past ten years. In: ROSEGREN, Erik; WENNER, Lawrence e PALMGREEN, Philip. (Eds.). Media Gratifications Research. Beverly Hills: Sage Publications, p. 1137, 1985.

PAPACHARISSI, Zizi e MENDELSON, Andrew L. An exploratory study of reality appeal: uses and gratifications of reality TV shows. Journal of Broadcasting \& Electronic Media, v. 51 (2), p. 355- 370, jun. 2007. Broadcast Education Association: Gale Group Broadcast Databases. Disponível em: <http://www. infotrac.galegroup.com>. Acesso em: 15 ago. 2014.

PERSE, Elizabeth M. Audience Selectivity and Involvement in the Newer Media Environment. Communication Research, London: Sage Publications, v. 17, n. 5, p. 675-697, 1990.

RUÓTOLO, A. C. F. Audiência e recepção: perspectivas. Comunicação e Sociedade. São Bernardo do Campo: UMESP, n. 30, p.159-170, 1998.

RUBIN, A. M., e RUBIN, R. B.. Contextual age and television use. Human Communication Research, v. 8, p. 228-244, 1982.

RUBIN, A. M.. Television Uses and Gratifications: The interactions of viewing patterns and motivations. Journal of Broadcasting, v. 27, p. 37-51, 1983.

RUBIN, A. M.. Ritualized and Instrumental Television Viewing. Journal of Communication, v. 34, n. 3, p. 67-77, 1984.

RUBIN, Alan e PERSE, Elizabeth. Audience Activity and Television News Gratifications. Communication Research, London: Sage Publications, v. 14, n. 1, p. 58-84, February, 1987.

RUBIN, Alan e PERSE, Elizabeth. Audience Activity and Television News Gratifications. Communication Research. London: Sage Publications, v. 14, n. 1, p. 58-84, 1987.

RUBIN, A. M.. Media uses and effects: a uses-and-gratifications perspective. In: BRYANT, Jennings; ZILLMANN, Dolf. Media effects: Advances in theory and research. 
Washington DC: Kent State University, 1998.

RUGGIERO, E Thomas. Uses and Gratifications Theory in the 21st Century. Mass Communication \& society, v. 3, n. 1, p. 3-37, 2000.

SWANSON, David L. Understanding audiences: Continuing contributions of gratifications research. In: Poetics, v. 21, p.305-328, 1992.

WIMMER, Rogeu; DOMINICK, Joseph. La Investigación Científica de la Comunicación. Barcelona: Bosh, 1996.

Recebido em: 30/4/2015

Aceito em: 19/5/2015

Endereço do autor:

Raquel Marques Carriço Ferreira <raquelcarrico@gmail.com>

Universidade Federal de Sergipe, Centro de Educação de Ciências Humanas.

Av. Marechal Rondon, S/N - DCOS - Cidade Universitária Prof. José Aloísio de Campos

Jardim Rosa Elze

49100-000 - Sao Cristovao, SE - Brasil

Telefone: (79) 21056919 